\title{
@SAGE researchmethods cases Researching Ethnicity and Ethnic Politics Using a Single Case Study Method
}

Contributors: Zerihun Abebe Woldeselassie

Pub. Date: 2019

Access Date: January 14, 2019

Academic Level: Postgraduate

Publishing Company: SAGE Publications Ltd

City: London

Online ISBN: 9781526473011

DOI: http://dx.doi.org/10.4135/9781526473011

(C) 2019 SAGE Publications Ltd All Rights Reserved.

This PDF has been generated from SAGE Research Methods Cases. 


\section{Abstract}

This case is a study on ethnic politics in Ethiopia, using an interpretive methodology in the present context of the growing importance of ethnicity in politics across the globe. It primarily focuses on the ways in which a single case study on ethnicity and politics could be empirically performed. The case helps to understand the advantages and challenges of a single case study method in researching political mobilization and claimmaking through identity and belonging formation. In addition, it discusses practical challenges one may navigate through during fieldwork on ethnic politics.

\section{Learning Outcomes}

By the end of this case, students should be able to

- Learn how to contextualize a single case study focusing on ethnicity and politics

- Examine epistemological and ontological issues pertinent to case study of ethnic politics

- Know the benefits of a single case study in researching ethnic politics

- Learn some challenges and lessons in using a single case method in researching ethnicity and politics

- Be aware of some the practical challenges while conducting fieldwork in researching ethnic politics

\section{Project Overview and Context}

Despite its high relevance in a case study method, the concept of context is rarely discussed in the relevant methodology literature, particularly in relation to conducting an empirical research on ethnicity and politics. Context in a case study approach should be seen as much empirical as it is conceptual, and has to be selected and constructed by the researcher in light of his or her own assumptions and frames of reference that make the research meaningful in terms of a specific research topic and problematics.

The fact that context has a dual aspect, that is, both empirical and conceptual, means that to contextualize is to both frame and make the case knowable from a specific ontological assumption, epistemological orientation, analytical frames, and knowledge tradition. Hobart once noted that the question of context also raises the issue of knowledge and power. "Contextualization raises the delicate issue of the relation between analysts" and indigenous frames of reference, and poses the question, whose formulation of relations and whose criteria of relevance are at stake? (Hobart, 1986, p. 8). In my research, the selection of my research topic, as well as the framing of the research problematics, was based on both my own and my informants' frames of reference and existing situation, which includes my theoretical choice, the contemporary political developments in my country, earlier research experience, and personal ethnic background. 


\section{Theoretical Choice}

Although ethnicity in recent social theory is widely conceptualized as a socially constructed, dynamic, and historically contingent phenomenon, it is, in present day nationalist politics, treated as a given or inevitable reality. Known as primordialism, the fixation of ethnicity by ordinary folks, nationalist elites, and analysts is often considered as an act of reification. However, essentializing ethnicity is not merely a question of reification, that is, giving a specific content and form to ethnic categories. It also entails a wider sociopolitical significance. Hall (2000) once noted, "The more 'ethnicity' matters, the more its characteristics are represented as relatively fixed, inherent within a group ..." (p. 223). By adopting a social constructivist perspective, I treated the naturalization of ethnicity in the public space as a political phenomenon that needs to be described and analyzed in its own contexts. The term political here implies more than the commonplace notion of instrumental rationality in ethnic politics. On one hand, it implies the question of why, how, and when ethnicity has become relevant in issues of representation, governance and equality, on the other, it refers to the issue of how ethnicity becomes a critique of (established) politics itself.

\section{Contemporary Problem}

My focus on the recent political development in Ethiopia has to do with its relevance in providing a good opportunity to explore and analyze the contemporary political significance of ethnicity in a specific context. I am referring to the post-1991 political change in the country that began with the complete collapse of the "socialist" dictatorship (1974-1991), through an ethnic-based armed coalition movement known as the EPRDF (Ethiopian People's Revolutionary Democratic Front, which is still in power) in which ethnicity came to be seen as natural and fixed. Once in power, the EPRDF began the reconfiguration of the Ethiopian empire-state along ethnic lines, dividing the hitherto centralized sovereign state power into regionalstates for larger ethnic groups, and politico-administrative "districts" and "zones" for smaller ones. As a student of ethnicity and nationalism, I became interested in researching ethnic identification and belonging, classification, mobilization, competition and claim-making as the most important political challenge for the future of peace and stability of the country.

In fact, the Ethiopian situation is an aspect of the contemporary growing importance of ethnicity in politics across the globe. It took place at a time when researchers were interested in what Fraser (1997) referred to as a "shift in the grammar of political claims-making from claims of social equality to claims of group difference," which globally defines the "post-socialist condition" (p. 2). Thus, I use the term post-socialist to refer to two aspects of the case. On one hand, it refers to the temporal dimension of the case, in which the global context of the research is delimited to the contemporary growing importance of ethnicity in politics after socialism. On the other hand, it refers to the spatial aspect of the case that situates the case to a specific space, in which ethnicity has become significant in terms of a particular event or phenomenon.

\section{Earlier Research Experience}


2019 SAGE Publications, Ltd

The interest in researching ethnicity and politics was in fact a build-up from my previous research interest and experience. In 2001, I conducted a study on an indigenous Muslim (minority) group in north-west Ethiopia called the Weyto, who identified themselves as Muslim, but whose self-identification was not recognized by the non-Weyto, Amhara-Muslims, who categorize the former as non-Muslim or polluting Islam. In my thesis, I have raised issues of identity, power, and internal complexity. I argued that despite the claim, ethnic federalism in Ethiopia did not consider diversities within politically legitimized identity groups. I have also shown that the situation of many indigenous groups like the Weyto was much more complex than what was formally recognized by the state. Using a different case material, I designed my study by adopting a similar approach, critically reviewing the existing relevant research and focusing on the meaning and political significance of ethnicity.

\section{Personal Ethnic Background}

The focus on the meaning and significance of ethnicity partly related to my own personal ethnic background and lived experience. I am referring to how issues of personal experience of identity and belonging affect the choice of a topic and the study in general. I was born and raised in Addis Ababa, which is a multi-ethnic center and the capital city of Ethiopia. My parents have a mixed ethnic background from what are now called the Siltie and Oromo nationality groups. Nevertheless, as a child, I grew up in a multi-ethnic setting with an identity as an urban, Orthodox Christian and Amharic-speaker. This identity formation is by no means identical with or reducible to what is now politically recognized as Amhara nationality in post-1991 Ethiopia. I was in fact aware of the different ethnic backgrounds within my family. Nevertheless, I have never identified with or felt attached to a single ethnic category whatsoever. Neither significant others ascribed the identity Amhara to me based on the language I have been speaking from birth. Following the post-1991 political change in Ethiopia, however, the government made language-based ethnic identities the basis for state classification, which was relevant while selecting my research topic, as it sharply contrasted with or undermined my own personal mixed ethnic background and lived experiences.

\section{The Case}

Whereas case study remains an important method in the social sciences, there is often a commonplace question among researchers regarding how to determine whether and when to use the case study as a research method. My experience shows that even if there is no single formula that helps determine if one must use the case study method, the specific research questions one is attempting to answer largely determine whether the case study method is appropriate or relevant in researching ethnicity and politics.

The selection of the case study method for my research was directly connected to a specific event that occurred in 2001 in which a population, which, up until then, was known as Eastern Gurage were presented with a unique referendum to determine if their ethnic identity was "Gurage" or "Siltie." As a part of reconfiguring the state and formally classifying the Ethiopian populations into ethnic governable nationality 
2019 SAGE Publications, Ltd

groups, the referendum was the culmination of a 10-year (1991-2001) political processes, including mobilization, claim-making, contestation, violent conflict, and institutional arbitration. The outcome of the referendum was that the majority Eastern Gurage population voted for a separate identity named Siltie, and since then, the Siltie Zone was established, representing one of the many nationality groups of the newly established Ethiopian ethnic federal political structure in the Southern regional state.

Even though what type of data I would exactly collect, and how I would analyze it was not clear during the designing of the research project, I had a clear research question and a broader idea of what kind of data would be relevant to the research. I wanted to answer the questions of how and why Siltie identity was formed and why and how it became political, and what were its cultural, social, and historical contexts? The case study method was thus relevant to document and analyze the specific case of ethnicity formation, its relevance in politics and the associated political conflicts. It was intended to produce knowledge for further comparative case studies.

My finding revealed four major points. First, by treating ethnic categories as homogeneous solidarity groups, the existing studies did not fully account for diversities within the Eastern Gurage population. Second, cultural difference was not the primary factor in the political mobilization, claim-making, and contestation of Gurage versus Siltie ethnicity. Third, ideologies based on clanship, classification promoted and legitimated by the state, elites' competition for resource and Islamic reformism were much more relevant factors to help understand the political significance of ethnicity in the region. Fourth, rather than revitalization, the formation of Siltie ethnicity represents a transformation of the historically established ethnic relations and political processes in the region.

\section{Fieldwork and Research Practicalities}

In conducting my fieldwork, I had to navigate through a number of practical challenges that directly or indirectly affected the data collection processes. One relevant challenge had to do with the question of a researcher's identity or ethnic background while researching other's ethnicity or identity. When I left to carry out my fieldwork, I was not prepared for the possibility that individuals in this setting would attribute a variety of different statuses and identities to me, and that this would affect, at least in part, the fieldwork and the research process. Despite the fact that I presented myself as an Ethiopian and a researcher, I was not treated well and accepted in every fieldwork situation with this identity and status.

Some people questioned my motive, interest, and reason to come to the area and study them. It was as if ethnic politics was exclusively a local resource or matter, in the sense that as an (ethnic) outsider, I had no privilege to conduct a study about the local people's identity and politics. The implication was clear to me: Either I had to be a part of that ethnicity or I had to pay people I had talked to so that my presence in the field would be accepted or tolerated, even if it may not normally have been accepted.

Initially, all this appears to confirm the commonly held assumption of many ethnographic case study 
2019 SAGE Publications, Ltd

researchers, namely that a researcher's identity (whether it is ethnic, religious, gender, racial, etc.) could often possibly negatively affect or limit access to and the gathering of data during a fieldwork. Yet, during the course of my fieldwork, I came to realize that this also relates to the question of the politicization and commercialization of ethnicity or social identity in the post-socialist world on one hand, and the question of how and why we produce knowledge regarding a certain population in the first place on the other.

The fact that this is a context in which political claim-making is constructed in terms of notions of social and cultural differences, rather than political equality, means whose interest one is reproducing or representing has become a sensitive question. To what extent then is one considering issues of power relations, belonging, and representation in knowledge production processes? Although not all these questions were answered based on my limited experience, rather than focusing on how my identity would limit my access to data, I developed a strategy of contextualizing my encounters and critiquing power on one hand and negotiating with the locals on the other.

For example, because people perceived me as a person who was not attached to the local authorities, there were a number of individuals eager to tell me about "the problems" they face due to the "unfair" decisionmaking of the local officials on many everyday state-society relationships. That means that instead of limiting my access to data, the way people perceived me had also facilitated the opening up of the locals for further negotiation, therefore gathering data depending on how I personally interacted and communicated in every situation.

\section{The Benefits of the Case Study Method}

In his discussion of the relevant points in case selection processes, Yin (1994) argues that a researcher needs to determine whether the purpose of his or her research is testing a theory, documenting a rare case, analyzing a phenomenon, or exploring a case in preparation for a multiple case design. In my study, there were three major significances in the case.

\section{Documenting the Case}

The very fact that the claim and assertion of Siltie ethnicity was the only event in Ethiopia, in which a population was offered a referendum on ethnicity, means that the single case study method was useful and relevant to document the unique case in an exploratory fashion. Indeed, it is one of the benefits of a single case study method, especially in researching ethnicity, that it helps to produce knowledge about a population about which little is previously known.

\section{Testing Existing Hypotheses}

In fact, there were some recent studies made before I conducted my research. However, based on my critical reading of these studies, I had a number of empirical and theoretical questions. In addition to providing a 
2019 SAGE Publications, Ltd

detailed documentation, the case study was necessary to provide an alternative to the existing description and theoretical explanations. This means that the case study method creates the opportunity to test existing theoretical explanations in the comparative study of ethnicity and politics.

In general, the case study method or qualitative methodology has often been considered useful, with regard to theory development or the articulation of new concepts and frameworks, though there is criticism regarding its relative weakness in hypothesis testing. In my study, however, I had the opportunity to both illustrate and challenge at least some of the existing descriptive, as well as theoretical claims of the case.

For example, although there exists a familiar assertion in the literature that ethnicity is politically constructed and manipulated, case studies of the actual process of that social, as well as political, construction and manipulation, specifically ethnographic accounts at the local level, are rarely offered. The purpose of my study hence included illustrating some of the existing conceptions of ethnicity in the social sciences using a detailed account of the case.

I had also challenged some hypothesis regarding ethnicity and political conflict in general, and Siltie versus Gurage identity politics in particular. One commonly held assumption states that ethnicity is essentially built on a notion of origin and ethnic conflicts, and that contestations have to do with competition for scarce resources within or across state boundaries, often corresponding with cultural differences. While competition for scarce resources may partly explain political conflict related to Siltie ethnicity, my study has shown, though contrary to the existing hypotheses, that this did not correspond to strict cultural boundary or the actual shared cultural attributes, including notion of origin, language, and religion.

I have argued that ethnic-related political conflicts and contestations might relate to diversities with regard to generations, status, integration, and clan dimensions, both within and across categories and groups. I have also shown that identity formation and political conflict may entail the growing political importance of maintaining, changing, or fixing ethnic boundaries, in contexts where greater social and cultural similarities (rather than differences) or crosscutting ties do exist due to political economy that covers empire-state formation, regional trade relations, and religious and demographic factors.

\section{Exploring the Case}

Most importantly, the case study method was useful in exploring new explanations or insights in relation to the meaning and social and political significance of ethnicity, especially in societies divided along clan lines. Although the comparative study of ethnicity and politics often focusses on societies divided along linguistic and religious lines, case studies of ethnicity and politics, particularly in societies sharing a common language but internally divided along clanship and locality, have rarely been theorized.

The commonplace and deductive theoretical explanation is that communities organized along clan ideologies form ethnic identities, often expressed through a shared notion of origin that ideologically legitimizes a subjective feeling of "we-hood" in the form of an individual-writ large kind of collectivity. However, because 
2019 SAGE Publications, Ltd

this conception did not explain the case of the Siltie, I have inductively proposed a new conception that may further problematize or develop the comparative study of ethnic politics, particularly in clan-based societies. In this regard, I suggested that a researcher on ethnic politics might consider a conceptual distinction between the concepts of identity and belonging. Based on the case material, I have argued that despite its significance in explaining fluid and situational socio-political processes, the concept of identity, unlike that of belonging, has limitation in fully capturing lived experiences, subjectivities and positions within such societies.

\section{Method in Action: Challenges and Lessons Learned}

In designing my case study, my plan was to study ethnicity and politics in Ethiopia by taking the case of the Siltie, assuming that the category of Siltie represents the case, that is, an ethnic group, meaning that it implies a temporally and spatially defined object of inquiry or unit of analysis. However, during the actual data collection, as well as the presentation processes, I faced four major challenges directly related to the application of the case study method.

\section{The Case in the Actual Research}

I came to learn that "Siltie" as an ethnic category was only a post-1991 phenomenon and that taking such a category as evidence for the historical existence of a corresponding identity or interest group would only undermine a possible transformation, rather than a continuity of ethnicity in the region. Thus, I have changed the unit of analysis from the Siltie to the Eastern Gurage, with the focus becoming the processes of forming a separate ethnicity for the Siltie from the wider Eastern Gurage population. This was the major weakness of previous studies, in that instead of explicating its historical and dynamic nature, they became implicated in the naturalization, thus politicization, of Siltie ethnicity.

\section{The Nature of Data Evidencing the Case}

Even though I had planned to treat the category Siltie representing the case, what I learned then was that in the actual fieldwork, I could only observe and learn about social situations, relationships, events, practices, and categories that could not easily be reduced to a single phenomenon whatsoever. This has been significant because it raises the question of what kind of data one collects using a single case method in a study of ethnic politics.

One way I have dealt with these challenges was similar to what Bennett and Checkel referred to as processes tracing. Using ethnography, formal and informal interviews, local publications, and government documents, I have attempted to document the different events, practices, and discourses that constituted, and hence may explain, the historical background, emergence of Siltie ethnicity, and its significance in politics. While it helped to construct the case vis-à-vis actual events, this approach also provided me with methodological tools to collect "evidence on processes, sequences, and conjunctures of events within [the] case for the 
2019 SAGE Publications, Ltd

purposes of [...] developing or testing hypotheses about causal mechanisms that might causally explain the case" (Bennett \& Checkel, 2012, p. 10). As such, my data have become ethnographies of ethnic classifications, rationalities, stories, worldview, and interpretations of actual events or situations that explain not only how a separate Siltie ethnicity is formed from the Gurage but also how it became a politically significant phenomenon in the region.

\section{Delimitation of the Case}

There was also the question of how does one deal with multiple categories and boundaries while conducting a single-case study of ethnicity? In addition to "Siltie," there were a number of other categories and boundaries, based, for example, on religion, clanship, locality, and state classification. As these categories had locally recognized historical, social, and political significance, the issue I have is to then define them as identity groups or basis of identifications, as is commonly done in much of the comparative studies of ethnicity and politics, or do I have to focus on some rejecting the others, on what basis and criteria, and why?

Looking into the relevance of the case study approach in much of qualitative methodology, there is an assumption that there must be something in the case at the ontological level that serves as the basis for comparing ethnicities. In a recent discussion related to the advantage of a single case study, Bennett and Elman (2010) have also noted that, "Just as language and concepts are inherently comparative, all single case studies, even when not explicitly comparative, are implicitly so" (p. 6).

This claim, although generally valid, also leads one to raise the important question of what exactly we are comparing in case studies of ethnic politics. Often language- or religious-based "us" and "them" distinctions, boundary making, or constructions of the other are considered as the most fundamental and universal processes. Although contextually relevant, these processes may not always explain the diversity and complexity of what is often considered as ethnic politics.

For example, I have problematized whether we can treat social and political identifications processes as identical phenomenon with processes of social and political belonging in a single case study of ethnicity. In fact, much of the discussion in the comparative study of ethnicity and politics does not distinguish between identity and belonging. Nevertheless, the case of the Siltie indicates that processes of social and political identification on one hand, and social and political belonging formation on the other, although related, need to be treated as distinct phenomena.

\section{Reflexivity and Power}

The fourth challenge had to do with the relationship between my research method, lived experience, and knowledge production processes (Gunaratnam, 2011). There are two aspects of this challenge. First, this relates to the question of how reflective I am regarding my ethnic background or notion of identity vis-àvis my informants' or interlocutors' notions and claims of ethnicity or identity. Although this includes the 
2019 SAGE Publications, Ltd

commonplace discussion of reflexivity in research, I am emphasizing the possible relevance of a researcher's lived experience and ethnic background in knowledge production processes in general. In my research project, my specific ethnic background and academic experience was relevant to learn, problematize, and critically analyze the meaning and socio-political significance of ethnicity in a reflective and ethnical manner. It has helped me to construct what I have analyzed as empirical data in a way I would not have done had I been solely dependent on the case in a positivistic fashion, or what the locals said about their ethnicity during data collection processes.

Second, this also relates to the question of a researcher's position regarding power vis-à-vis ethnic mobilization and political claim-making, particularly in a situation like Ethiopia, where the context of the research itself was ethnicized and politicized. I am referring to a situation in which the state and the local elites were directly involved in the construction, classification, and objectification of ethnicities as an aspect of state reconfiguration in a post-socialist context. How can a researcher operate in such a context, insofar as speaking truth to power, and rationally and critically analyzing ethnic politics at the same time? In fact, the expectation from local officials and politically active local elites was that I would produce a knowledge that sympathizes with the locals' or government's understanding and practices of ethnicity and politics. Yet, the choice was clear to me; do I take ethnicity for granted, hence objectifying what the powerful (and powerless) say about (their) identity, or will I take the risk of interrogating power, being critical to the point of challenging some of the state's and locals' claims? My position has been the latter, and by so doing not only did I make myself relevant to the entire knowledge production process, but I also preferred to "speak truth to power."

\section{Conclusion}

This case study has been concerned with explicating the ways in which a single case study of ethnicity could be empirically performed. In so doing, I have provided the overview and context of the research, as well as the selection of the case, followed by the discussion regarding the benefits and challenges of the case study and the lessons learned during the actual research fieldwork or research processes. There are three key points I would like to emphasize in relation to how we should treat the case in a single case study of ethnic politics.

First, there is the commonplace argument that the use of case study research in the comparative study of ethnicity and politics entails a realist epistemological orientation in which reality and data are often considered as objective and measurable. Withstanding the validity of this claim in a number of contexts, an empirical qualitative case study of ethnicity formation and ethnic-related political processes, largely entails an interpretivist epistemology, in which what is considered as real is either contested or becomes contingent on the relevant contexts pertinent to the understanding and explanation of the case. The methodological significance of this epistemological orientation is that it helps to document and understand lived experiences and subjective claims as important elements of data or evidence.

Second, although ethnic groups and categories are often taken for granted as representing the case, my research has shown that what is taken as the case is neither something given a priori nor homogeneous. In 
2019 SAGE Publications, Ltd

this regard, Bennett and Checkel rightly noted that as a class of events, cases must be treated as "the social constructions of both political actors and the social scientists who study and define political categories. They are not simply given to us by history, but defined by our concepts ..." (Bennett \& Checkel, 2012, p. 11). This means that rather than being a fixed ontological entity, a case in a study of ethnic politics is often meaningful or knowable vis-à-vis the context of the research, which includes the analysts and informants' frames of references. Similarly, the delimitation of the case is also not something given. Instead, it largely depends on our empirical focus and theoretical conceptualization with regard to the temporal and spatial aspects of the case.

Third, a case study of ethnic politics should also address ethical issues and reflectivity while researching others' subjectivities and lived experience in the form of politics of identity and belonging. More importantly, this should be accomplished without losing a critical approach in the sense of interrogating different actors including the state, political elites, or ordinary subjects with regard to power positions, claims of truth and difference, legitimacy, and rationalities in politics of identity and belonging.

\section{Exercises and Discussion Questions}

1. How do you contextualize your unit of analysis in a single case study of ethnicity?

2. What other advantages and limitations can you suggest in the use of a single case study method in researching ethnicity and politics?

3. How do you respond if people question your interest and motive to study others' ethnicity?

4. What do you do so that the way people perceive you in the fieldwork situation does not limit your ability to gather data?

5. What measure do you take so that your identity and perspective does not affect your findings?

\section{Further Reading}

Gunaratnam, Y. (2011). Researching "race" and ethnicity. London, England: SAGE.

Wimmer, A. (2009). Herder's heritage and the boundary-making approach: Studying ethnicity in immigrant societies. Sociological Theory, 27, 244-270.

\section{References}

Bennett, A., \& Checkel, J. T. (2012). Process tracing: From philosophical roots to best practice (Simons Papers in Security and Development, No. 21/2012). Vancouver, British Columbia, Canada: School for International Studies, Simon Fraser University.

Bennett, A., \& Elman, C. (2010). Case study methods. In C. Reus-Smit \& D. Snidal (Eds.), The Oxford 
2019 SAGE Publications, Ltd

handbook of international relations (pp. 1-20). Oxford, UK: Oxford University Press.

Fraser, N. (1997). Justice interrupts: Critical reflections on the "post socialist" condition. New York, NY: Routledge.

Gerring, J. (2004). What is a case study and what is it good for? American Political Science Review, 98, 2341-2354.

Gerring, J. (2007). Is there a (viable) crucial-case method? Comparative Political Studies, 40, 3231-3253.

Hall, S. (2000). Conclusion: The multicultural question. In B. Hesse (Ed.), Un/settled multiculturalisms: Diasporas, entanglements, transruptions (pp. 209-241). London, England: Zed Books.

Hobart, M. (1986). Introduction: Context, meaning, and power. In M. Hobart \& R. H. Taylor (Eds.), Context, meaning, and power in Southeast Asia (pp. 7-10). Ithaca, NY: Cornell Southeast Asia Program (Studies on Southeast Asia).

Stake, R. E. (2008). Chapter 4: Qualitative case studies. In N. K. Denzin \& Y. S. Lincoln (Eds.), Strategies of qualitative inquiry (pp. 119-150). Los Angeles, CA: SAGE.

Yin, R. K. (2009). Case study research: Design and methods. London, England: SAGE. 